\title{
Analysis of effect on $\mathrm{CO}_{2}$ emission reduction and cost estimation for the use of Bio-coke: a case study of Osaka, Japan
}

\author{
Yukari Fuchigami $^{1} \cdot$ Keishiro Hara $^{1} \cdot$ Takeo Kita $^{2} \cdot$ Michinori Uwasu $^{1}$ • \\ Shuji Kurimoto ${ }^{1,2}$
}

Received: 23 June 2015/Accepted: 4 September 2015/Published online: 5 October 2015

(c) The Author(s) 2015. This article is published with open access at Springerlink.com

\begin{abstract}
Bio-coke (BIC) is drawing attention as a coalcoke substitute in industry. Though BIC can be used as a carbon-neutral fuel, its overall benefits, including the environmental impacts associated with its production processes and its merits as an alternative fuel, remain unknown. In this study, we investigate the overall impacts and benefits related to BIC production processes and alternative fuel applications by looking into the case of Takatsuki in Osaka Prefecture, the only commercial BIC plant in Japan. Based on the system boundary set, we calculated $\mathrm{CO}_{2}$ emissions per ton of BIC associated with its manufacturing and transportation processes to be $1.01 \mathrm{t}$ $\mathrm{CO}_{2} . \mathrm{CO}_{2}$ emission from electricity consumed in the process was found to be the largest, accounting for $74.7 \%$ of total emission. The analyses also revealed that using one ton of BIC as alternative fuel in industry instead of coalcoke could result in avoiding 2.16 tons of $\mathrm{CO}_{2}$ emissions, showing a clear environmental benefit. While BIC's calorific value is almost same as pellet's, BIC had higher gross margin and energy density than pellet produced in the same facility. These findings enhance the merits of producing BIC from wood biomass and could lead the way to revitalizing forestry in Japan.
\end{abstract}

Yukari Fuchigami

fuchigami@ceids.osaka-u.ac.jp

1 Center for Environmental Innovation Design for Sustainability, Osaka University, Office for UniversityIndustry Collaboration, Building D, 6F, 2-1 Yamada-oka, Suita, Osaka 565-0871, Japan

2 Osaka Prefecture Forest Owners Association, 1052-1, OhazaHara, Takatsuki, Osaka 569-1051, Japan
Keywords Bio-coke $\cdot \mathrm{CO}_{2}$ emission $\cdot$ Alternative fuel . Net energy balance $\cdot$ Local forestry

\section{Introduction}

In Japan, forestry dilapidation and the weakening of regional economies caused by the decline of forestry have hindered the utilization of forest biomass. To use natural resources sustainably, we must consider not only environmental aspects, but also economic effects on local inhabitants and the significance of using techniques already in practice in the area. In the meantime, there are global-scale environmental issues such as the depletion of fossil fuel and global warming. Using energy derived from local forest biomass is now attracting attention as one of the ways to address the pressing issue [1,2]. Environmental conservation, economic activity, and area fixity are all important to the sustainability of forestry [3]. Environmental conservation through the use of local resources can become the key in accomplishing all three aspects. For example, biomass fuels such as wood pellets are considered to be a carbon-neutral energy resource. In addition, because the pellets are locally produced and consumed, local profit can be created [4].

In the late 2000s, Bio-coke (BIC) was developed by Kinki University (domestic patent no. 4089933) in Japan [5]. Since it has a high energy density, it can be used as a coal-coke substitute in large-scale industrial processes [6, 7]. The characteristics of BIC can be summarized as follows [6, 8]: (1) no raw materials are lost in the process of making BIC; (2) $100 \%$ of the energy in the raw materials is retained; (3) BIC has a high energy density, so its transport efficiency is higher than that of wood pellets, (4) BIC is a solid fuel suitable for storage and transport, and 
(5) stable combustion is possible at high temperatures, making BIC a suitable alternative to fossil fuels. Further, BIC can utilize not only unused biomass and thinned wood, but also construction waste and food residue. In other words, it can be the basis for a cascade recycling system for industrial wood waste. In general, however, the costs of forest maintenance exceed the profit it generates. In fact, forestry operation cannot be maintained without relying on subsidy. This problem has hindered the thinning of forests and the promotion of utilizing unused wood. BIC production has the potential to solve this problem by not only utilizing unused wood biomass, but also by stimulating industrial demand.

As of 2014, there is only one commercial BIC plant in Japan, run by the Osaka prefectural forest owners association (OFOA). Its BIC production supplies one manufacturing company in Aichi Prefecture, where it is used as an alternative to coal-coke. One of the raw materials for making BIC is thinned wood from the OFOA's forest management activities. However, demand for BIC is still limited and BIC production at present does not necessarily promote the utilization of unused wood in the region. We posit that the not knowing the actual benefits of producing and using BIC hinders the dissemination of BIC technology. Though BIC is used as a carbon-neutral alternative to coal-coke, its overall benefits, including the environmental impacts associated with its production processes such as $\mathrm{CO}_{2}$ emission, remain unknown. In fact, most previous research has focused only on the environmental aspects of using raw materials to make bio-energy products [9-12] and on BIC's physical and scientific characteristics as a fuel [13-15]. For example, Uchiyama et al. [16] estimated the $\mathrm{CO}_{2}$ emission reduction attainable by using $\mathrm{BIC}$ as a substitute fuel. Their study, however, did not include the estimation of any discharge at the time of production. Few studies have considered the total $\mathrm{CO}_{2}$ emissions (environmental impacts) of the entire process, from logging to consumption, and so BIC's actual net environmental benefits have not been clear.

In this study, we analyze the overall impacts and benefits of the OFOA's BIC production processes and of using BIC as an alternative fuel. Specifically, we (1) delve into environmental impacts $\left(\mathrm{CO}_{2}\right.$ emissions) associated with producing $\mathrm{BIC}$ and its energy balance; (2) compare the $\mathrm{CO}_{2}$ emissions, net energy balance, usability, and costs between BIC and wood pellets productions, and (3) investigate the $\mathrm{CO}_{2}$ emission reduction attainable using $\mathrm{BIC}$ as an alternative to coal-coke. The potential and significance of BIC production and use are elucidated by these analyses and the findings will shed light on the merits of producing BIC from wood biomass. The information and implication derived from the results could lead the way to revitalizing forestry in Japan.

\section{Method}

\section{Study sites}

The head office of the OFOA and one of its branches, the Mishima office, are located in Takatsuki city, north of Osaka (Fig. 1). Osaka Prefecture is $31 \%$ forest, making it the least forested of all of Japan's prefectures [17], but Takatsuki city has the third highest percentage of forest $(44 \%)$ in Osaka Prefecture [18]. BIC is made at a plant in the OFOA factory north of Takatsuki city. Wood chips, pellets, and compost are also made in these facilities. There are two plants in the factory. One is for BIC and the other is for pellets. The quantities of electricity and fuel used are periodically measured in each facility. Chips and compost are made outside. The raw materials for the biomass fuels are thinned wood produced by the OFOA's forest management activities and wood from forest development sites including the construction of the Shin-meishin highway in Osaka Prefecture started in 2009.

\section{Analysis of $\mathrm{CO}_{2}$ emission and energy balance}

Since the overall merit of Bio-coke utilization as carbonneutral energy source is best judged from the evaluation of $\mathrm{CO}_{2}$ emission, we aim to estimate $\mathrm{CO}_{2}$ emission as the proxy of greenhouse gas associated with producing Biocoke. One ton of BIC produced is the functional unit, and the system boundaries of the evaluation stretch from raising the raw material to consumption by combustion (Fig. 2). The processes of discharging combustion ash and handling coolant, and emissions from workers' commutes are outside the system boundary of analysis. We obtained data where possible from the OFOA in interviews or in the form of data sets. Note that we calculated $\mathrm{CO}_{2}$ emissions using the build-up method. Data that were difficult to acquire or measure were set based on previous research. As our main target is the processes involved in BIC production, other factors such as construction or maintenance of facilities and machines are not included in the evaluation. Energy inputs include fuels such as light oil, kerosene, gasoline, LP gas, mixed oil and multi-diesel oil, as well as electricity, all of which are used for the operation of BIC production in the case study site. The $\mathrm{CO}_{2}$ emission factors for fuels and electricity used in this study are shown in Table $1[19,20]$. We based our work on the data for a 2-year period from June 2012 to May 2014. No pellets or BIC were produced for several months. Even when no production is occurring, the production process is promoted along the way. Thus, we based our analyses on a 2-year average, not omitting data for the months when no fuel was produced. We also calculated the net energy balance 


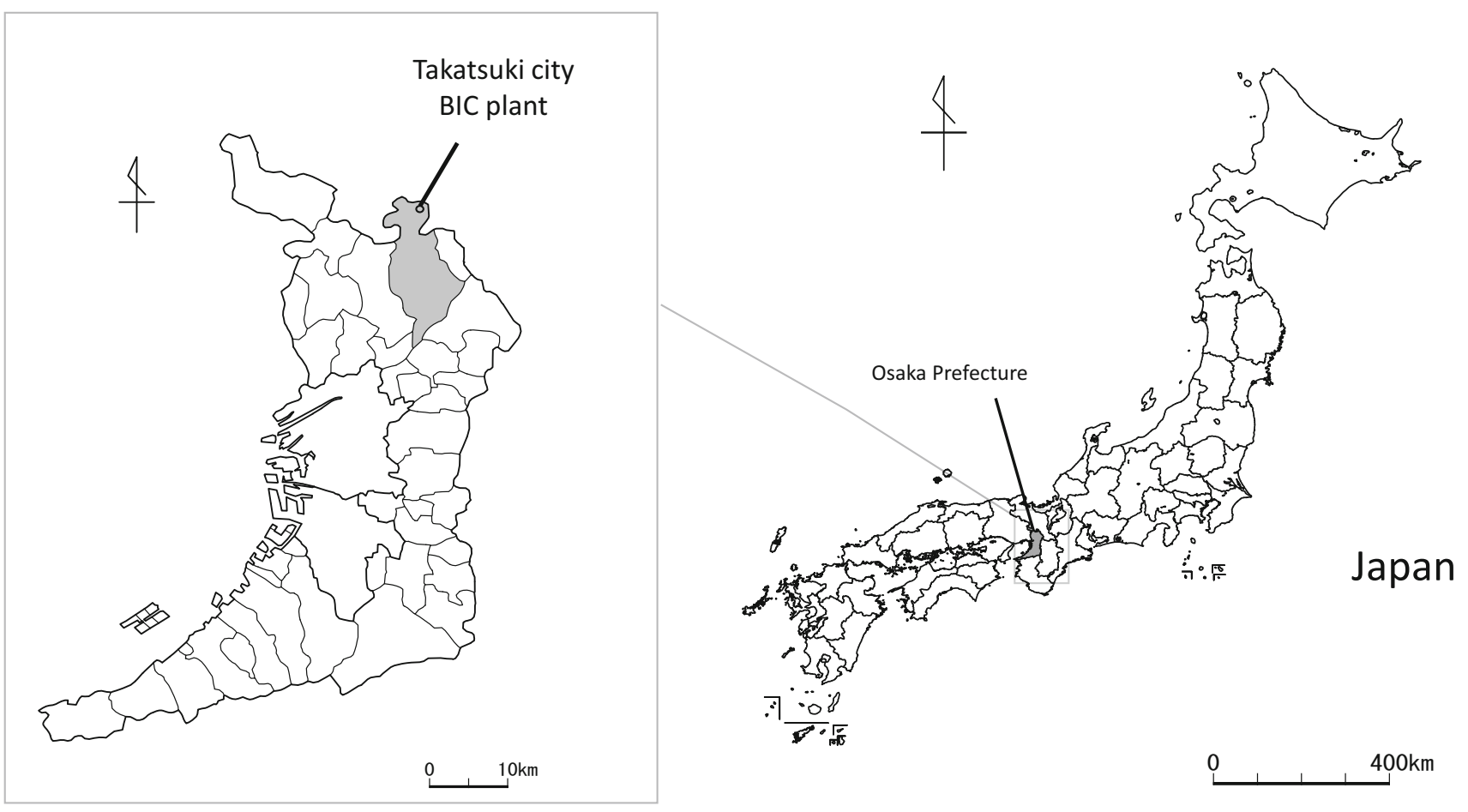

Fig. 1 Location of Bio-coke (BIC) plant. The map was drawn by authors using Mandara

(NEB). The NEB is used to compare amounts of biofuel energy and fossil fuel energy inputs. It is the ratio of energy output to energy input [21, 22]. Various fuels' calorific values per unit are shown in Table $2[23,24]$.

We used values from previous research data for the energy input required to obtain raw materials (processes I and II in Fig. 2). Specifically, we used the value of $17.5 \mathrm{~kg}$ $\mathrm{CO}_{2}$ as the average $\mathrm{CO}_{2}$ emitted in producing $1 \mathrm{~m}^{3}$ of thinned wood [25]. Hitoe et al. [26] examined the $\mathrm{CO}_{2}$ emission from silviculture through log production, showing that most of the environmental load was due to harvesting work, and that silviculture accounts for only $2 \%$ of the total environmental load. Therefore, the environmental load from silviculture was not included in this analysis. According to the MAFF [27], $1 \mathrm{~m}^{3}$ of wood used as a material input can produce $2.7 \mathrm{~m}^{3}$ of chips on the stock volume basis. We used the value of $0.08 \mathrm{~kg} \mathrm{CO} / \mathrm{km}_{2} \mathrm{~m}^{3}$ for the $\mathrm{CO}_{2}$ emitted by process II [25]. Along with thinned wood provided by the OFOA, most of the raw material comes from the construction site of the Shin-meishin highway, which on average is about $10 \mathrm{~km}$ away from the BIC plant. Because the sites where the OFOA thins the forest are also within the same area, a transport distance of $20 \mathrm{~km}$ round trip was used in process II.

For the manufacturing steps (processes III-X), we collected energy consumption data from June 2012 to May 2014 from the OFOA factory. We calculated the weighted average of the 26 months on a per unit production basis.
Processing (1) includes producing chips used as raw materials for pellet and BIC production and chips used directly for combustion or gardening. Therefore, we included the LP gas used in office operations in Processing (1). Also, interviews at OFOA revealed that producing 1 ton of pellets requires $8 \mathrm{~m}^{3}$ of chips and 1 ton of BIC requires $8.33 \mathrm{~m}^{3}$ of chips. In Processing (2), 0.2 tons of pellets, produced at the plant, are used as fuel to produce 1 ton of BIC. In the sales and distribution process (process $\mathrm{XI}$ ), BIC is transported to Toyota city in Aichi Prefecture. The transport distance was estimated to be $186.1 \mathrm{~km}$, using the range-finding website "Map Fan Web" [28]. We assume that this is a one-way trip because the company loads the truck in the return path to Osaka. We found that a 10-ton truck is used for the transport, and the average load is about 9.5 tons. According to a previous study, the fuel consumption of a 10-ton truck is $2.89 \mathrm{~km} / \mathrm{L}$ [29], which we used in our calculations.

\section{Results and discussion}

\section{$\mathrm{CO}_{2}$ emission from producing Bio-coke}

Table 3 shows the data collected to estimate the energy used in the relevant processes and each one's estimated $\mathrm{CO}_{2}$ emission. $\mathrm{CO}_{2}$ emissions per ton of BIC associated with manufacturing and transportation were calculated to 


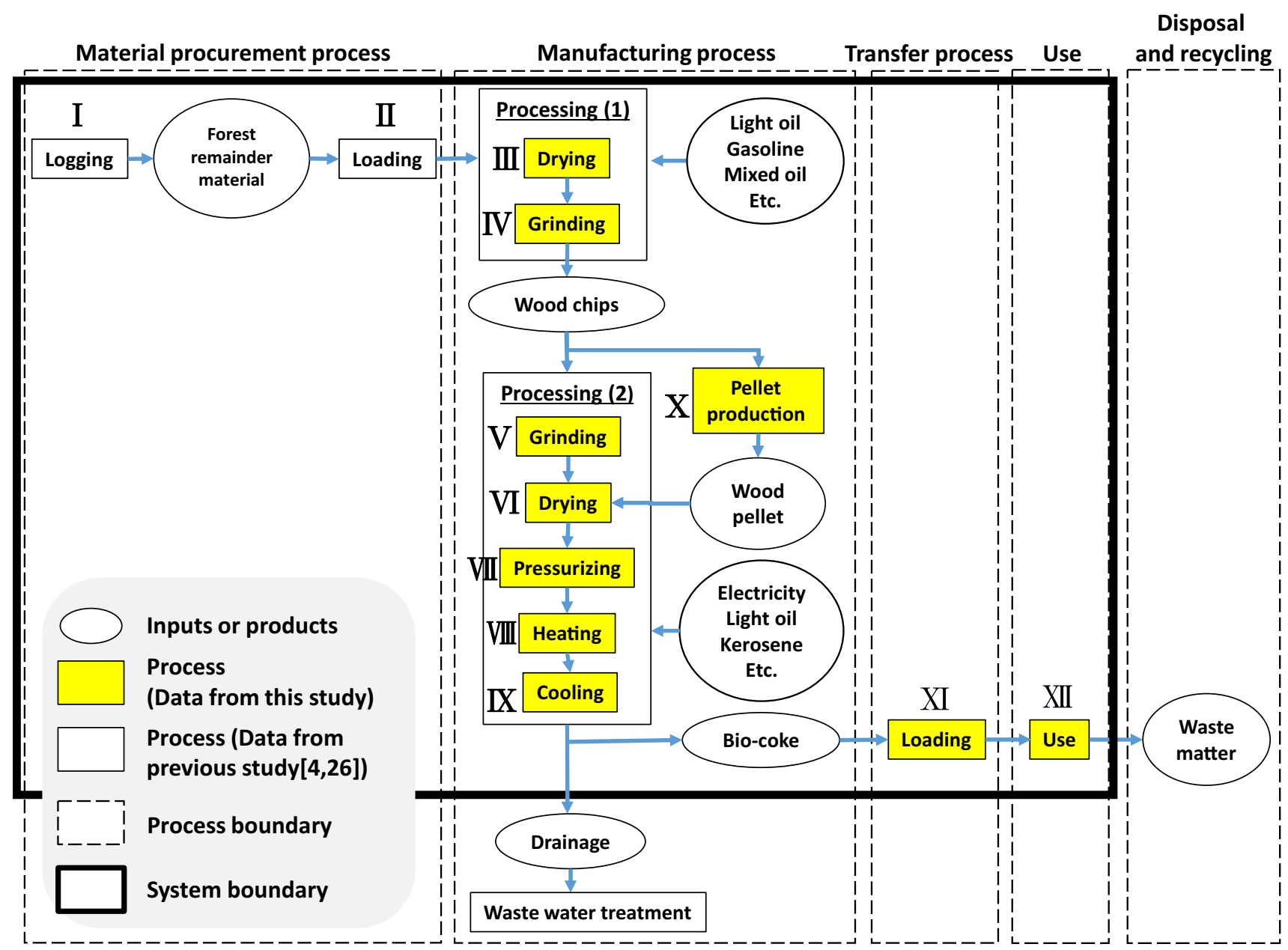

Fig. 2 System boundaries. Pellet production processes involve I-IV and X. BIC production processes involve I-IX. Details of the pellet manufacturing process are omitted in the figure and summarized inprocess $\mathrm{X}$

Table $1 \mathrm{CO}_{2}$ emission factors

\begin{tabular}{lll}
\hline Energy & $\mathrm{CO}_{2}$ emissions factors $\left(\mathrm{t} \mathrm{CO}_{2}\right)$ & Unit \\
\hline Electricity & $5.16 \times 10^{-4}$ & $\mathrm{kWh}$ \\
Light oil & 2.58 & $\mathrm{~kL}$ \\
Kerosene & 2.49 & $\mathrm{~kL}$ \\
Gasoline & 2.32 & $\mathrm{~kL}$ \\
LP gas & 3.00 & $\mathrm{t}$ \\
Mixed oil & 2.32 & $\mathrm{~kL}$ \\
Multi-diesel oil & 2.89 & $\mathrm{~kL}$ \\
Coal-coke & 3.17 & $\mathrm{t}$
\end{tabular}

Gasoline's $\mathrm{CO}_{2}$ emission factor was used for that of mixed oil, because mixed oil is mostly gasoline. Lubricating oil's $\mathrm{CO}_{2}$ emission factor was used for that of multi-diesel oil, because it is used as a typical lubricating oil for heavy equipment $[19,20]$

be 1.01 ton- $\mathrm{CO}_{2} \cdot \mathrm{CO}_{2}$ emissions from the manufacturing, obtaining raw materials, and sales and distribution processes are 91.3, 7.0, and $1.7 \%$, respectively. Notably, $\mathrm{CO}_{2}$ emissions from Processing (2) account for $82.8 \%$ of the
Table 2 Calorific value per unit

\begin{tabular}{lcl}
\hline Energy & Calorific value (MJ) & Unit \\
\hline Electricity & 3.6 & $\mathrm{kWh}$ \\
Light oil & 37.7 & $\mathrm{~L}$ \\
Kerosene & 36.7 & $\mathrm{~L}$ \\
Gasoline & 34.6 & $\mathrm{~L}$ \\
LP gas & 50.8 & $\mathrm{~kg}$ \\
Mixed oil & 34.6 & $\mathrm{~L}$ \\
Multi-diesel oil & 40.2 & $\mathrm{~L}$ \\
Pellets & 17.6 & $\mathrm{~kg}$ \\
\hline
\end{tabular}

Gasoline's calorific value was used for that of mixed oil, because mixed oil is mostly gasoline. Lubricating oil's calorific value was used for that of multi-diesel oil, because it is a typical lubricating oil for heavy equipment [23, 24]

total emissions. The processes involved in Processing (1) and (2) accounts for the large portion of overall $\mathrm{CO}_{2}$ emissions. 
Table 3 Energy consumed and $\mathrm{CO}_{2}$ emitted to produce 1 ton of Bio-coke

\begin{tabular}{|c|c|c|c|c|c|c|}
\hline Process & & Item & Amount & Unit & $\mathrm{t} \mathrm{CO}_{2}$ & $(\%)$ \\
\hline \multicolumn{7}{|l|}{ Input } \\
\hline \multicolumn{7}{|l|}{ Raw material } \\
\hline Energy & & $\begin{array}{l}\text { Chips for } 1 \mathrm{t} \\
\text { Bio-coke }\end{array}$ & $8.33 \times 10^{0}$ & $\mathrm{~m}^{3}$ & - & - \\
\hline $\begin{array}{l}\text { Obtaining raw wood material for } \\
\text { chips }\left(9.93 \mathrm{~m}^{3}\right)\end{array}$ & $\begin{array}{l}\text { Process I } \\
\text { Process II }\end{array}$ & - & - & & $\begin{array}{l}6.44 \times 10^{-2} \\
5.91 \times 10^{-3}\end{array}$ & 7.0 \\
\hline \multirow[t]{2}{*}{ Manufacturing } & $\begin{array}{l}\text { Processing (1) } \\
\text { (producing } 9.93 \mathrm{~m}^{3} \text { of chips) } \\
\text { Process III, IV }\end{array}$ & $\begin{array}{l}\text { Light oil } \\
\text { Gasoline } \\
\text { LP gas } \\
\text { Kerosene }\end{array}$ & $\begin{array}{l}3.26 \times 10^{1} \\
1.39 \times 10^{-1} \\
6.72 \times 10^{-5} \\
3.32 \times 10^{-2}\end{array}$ & $\begin{array}{l}\mathrm{L} \\
\mathrm{L} \\
\mathrm{t} \\
\mathrm{L}\end{array}$ & $\begin{array}{l}8.41 \times 10^{-2} \\
3.22 \times 10^{-4} \\
2.02 \times 10^{-4} \\
7.71 \times 10^{-5}\end{array}$ & 8.4 \\
\hline & $\begin{array}{l}\text { Processing (2) (Producing } 1 \text { t Bio-coke) } \\
\text { Processes V-X }\end{array}$ & $\begin{array}{l}\text { Electricity } \\
\text { Light oil } \\
\text { Kerosene } \\
\text { Multi-diesel oil } \\
\text { Pellet }\end{array}$ & $\begin{array}{l}1.46 \times 10^{3} \\
1.49 \times 10^{0} \\
8.21 \times 10^{-1} \\
5.28 \times 10^{-3} \\
2.00 \times 10^{-1}\end{array}$ & $\begin{array}{l}\mathrm{kWh} \\
\mathrm{L} \\
\mathrm{L} \\
\mathrm{L} \\
\mathrm{t}\end{array}$ & $\begin{array}{l}7.50 \times 10^{-1} \\
3.85 \times 10^{-3} \\
2.05 \times 10^{-3} \\
1.53 \times 10^{-5} \\
7.65 \times 10^{-2}\end{array}$ & 82.9 \\
\hline Product transfer & Process XI & Light oil & $6.78 \times 10^{0}$ & $\mathrm{~L}$ & $1.75 \times 10^{-2}$ & 1.7 \\
\hline Output product & Process XII & Bio-coke & $1.00 \times 10^{0}$ & $\mathrm{t}$ & 0 & 0.0 \\
\hline Total amount & & & & $\mathrm{t} \mathrm{CO}_{2}$ & $1.01 \times 100$ & 100 \\
\hline
\end{tabular}

Energy-related information was obtained from interviews with OFOA personnel. $\mathrm{CO}_{2}$ emissions associated with raising raw materials are from previous research [25]. $\mathrm{CO}_{2}$ emissions arising from chip production are not included for pellets

$\mathrm{CO}_{2}$ emissions from electricity ware the largest source by energy type, accounting for $74.7 \%$ of the total emissions and $90.1 \%$ of Processing emissions (2) (Fig. 3). This shows that most of the $\mathrm{CO}_{2}$ emissions come from electricity consumption. Given that about $80 \%$ of the electricity from Kansai Electric Power Company (KEPCO) originates from thermal power generation using coal-coke [30]. $\mathrm{CO}_{2}$ emission from electricity use tends to be high.

For comparison, a study by the new energy and industrial technology development organization (NEDO) estimates $\mathrm{CO}_{2}$ emissions from $\mathrm{BIC}$ production processes,

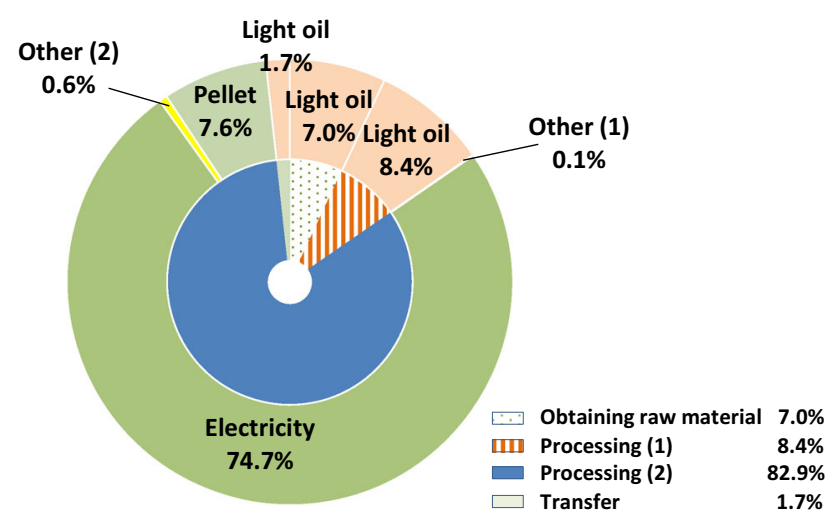

Fig. $3 \mathrm{CO}_{2}$ emissions by energy type and process. As "fuel" accounts for less than $1 \%$, it was included in "other". Other (1) includes gasoline, LP gas, and kerosene. Other (2) includes kerosene, multi-diesel oil, and pellets focusing particularly on electricity consumption, assuming that recycled tips are used as raw materials [24]. It reveals that theoretically, $1355 \mathrm{kWh}$ of electricity is needed to produce 1 ton of BIC. Using the values in Tables 1 and 3, $\mathrm{CO}_{2}$ emissions from BIC production are estimated to be $0.70 \mathrm{t} \mathrm{CO}_{2} / \mathrm{t}$. In our study, electricity consumption and associated $\mathrm{CO}_{2}$ emissions per ton of $\mathrm{BIC}$ produced under the same conditions are $1460 \mathrm{kWh}$ and $0.75 \mathrm{t} \mathrm{CO}_{2}$, respectively.

\section{Comparison to wood pellets}

We performed a study comparing BIC and wood pellets as similar wood biomass fuels in terms of the environmental impacts, NEB, usability, and costs associated with their production. Both are being manufactured at the OFOA facility. The system boundaries for the comparative analysis are based on processes I-X in Fig. 2. We excluded the transportation process, because our aim was to compare the two up to production at the Takatsuki factory.

Based on interviews with OFOA personnel, the calorific values of wood pellets and BIC are 4200 and $4438 \mathrm{kcal} / \mathrm{kg}$, respectively. Thus, there is not much difference between the two products in terms of calorific values, as both are made from the same raw materials. On the other hand, BIC is compressed densely, which allows it to be burned stably for a longer time. Thus, BIC can be used as alternative to coal cokes. $\mathrm{CO}_{2}$ emitted in the processes of pellet 
production is estimated to be $0.51 \mathrm{t} \mathrm{CO}_{2} / \mathrm{t}$, meaning that its environmental load is lower than that of BIC (Fig. 4). This is attributed to the fact that more electricity is consumed in the production of BIC than that of wood pellets.

Next, we compared the NEB of BIC and wood pellets. The NEB is a value obtained by subtracting the input energy at the time of fuel purification from energy of the fuel produced. This is an indicator of efficiency and an environmental performance of produced energy. We calculated the calorific value per unit $(\mathrm{MJ} / \mathrm{t})$ based on $1 \mathrm{MJ}$ being equal to $239 \mathrm{kcal}$. In this calculation, we again focus on the processes involved in producing both products, excluding transportation (process XI). We found that 0.27 and $0.6 \mathrm{MJ}$ of energy is input for wood pellets and BIC, respectively, to generate output energy of $1 \mathrm{MJ}$ (Fig. 5). More specifically, the NEB ratio for wood pellets is 3.67 while that of BIC is 1.67 . We then consider the usability of the two products. The specific gravity of the pellets is between 0.6 and 0.7 while BIC's is between 1.2 and 1.4. This is mainly because the BIC is compressed more densely than the pellets. This also means that BIC has a higher energy density, which allows more efficient transportation. Furthermore, BIC can burn stably for long hours because it is compressed very densely. Because of these characteristics, BIC can be used in a blast furnace as an alternative to coal-coke. Thus, BIC can be expected to be used as an industrial heat source (note that BIC is transported to a company in Aichi Prefecture as an alternative fuel).

We then attempt to make rough estimates of production costs based on the costs of raw material, electricity, and fuel used in the processes (Table 4) for a comparison purpose. Note that we pay attention to costs for raw materials and energy consumption to simplify the estimation. Raw materials are thinned wood from the OFOA and industrial wood waste from other sources. Based on our interviews with OFOA personnel, the purchase price of thinned wood from the forestry section of OFOA is 6500

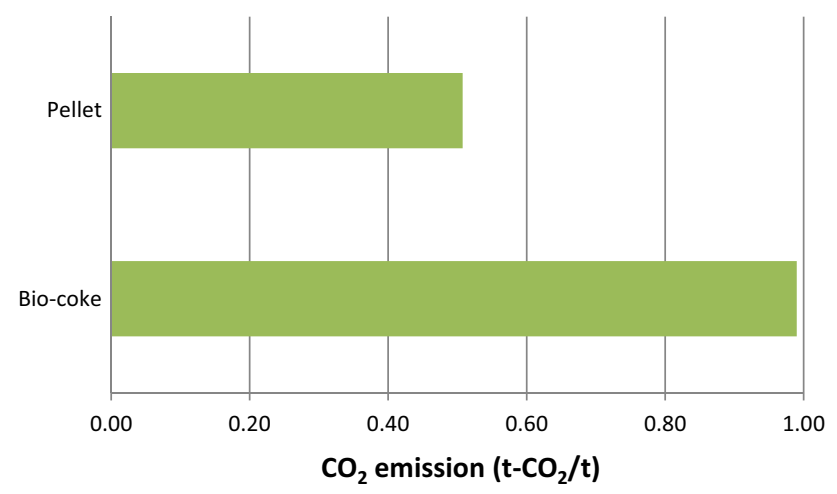

Fig. 4 Comparison $\mathrm{CO}_{2}$ emission of Bio-coke (BIC) and pellet in the factory of Takatsuki. Product transport process is not included in this data

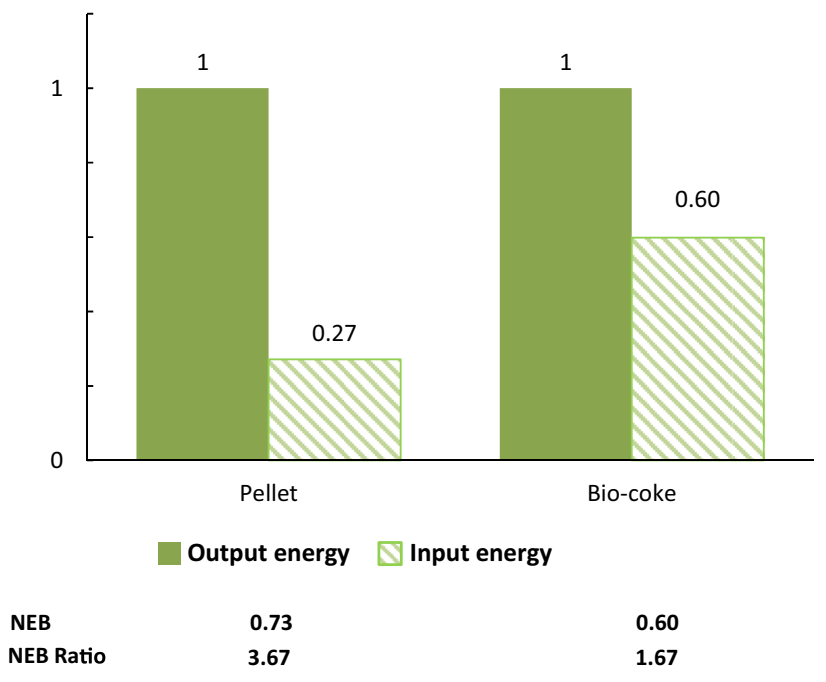

Fig. 5 Comparison net energy balance (NEB) of BIC and pellet in factory of Takatsuki. Product transport process is not included in this data

yen $/ \mathrm{m}^{3}$. We found that the thinned wood accounts for less than $5 \%$ of the total raw materials. The majority of raw material comes from industrial wood waste, for which disposal fees can be obtained instead. We therefore did not include the cost of purchasing raw materials from OFOA in the estimation, as it is almost negligible. The fees for waste disposal vary depending on the type of material, such as branches, trunks, or root parts. We assumed that wood branches are the industrial wood waste most used as a raw material and applied their price of 18,000 yen/t as listed in the OFOA price list [31]. Production cost was calculated from usage and each price, the cost of electricity was obtained from interviews with OFOA and we used the price of fuel as of April 2013, available from the data of agency for natural resources and energy [32], along with information on the amount of fuel used. According to the OFOA, the water bill is between 3000 and 4000 yen per month for the entire plant, so we concluded that the cost for water is relatively small given the amount used and did not include it in the estimation. Again, personnel expenses and initial and maintenance costs of the facilities were excluded as well, because we focused only on the costs for raw

Table 4 Costs and selling prices of Bio-coke and pellet

\begin{tabular}{lll}
\hline & Pellet & Bio-coke \\
\hline Cost of raw material (yen/kg) & -18 & -18 \\
Cost of production (yen/kg) & 40.8 & 28.0 \\
Total cost (yen $/ \mathrm{kg})$ & 22.8 & 10.9 \\
Selling price (yen $/ \mathrm{kg})$ & 46 & 50 \\
\hline
\end{tabular}

Raw materials are collected with fees for waste disposal. This can be counted as revenue, and is therefore shown as a negative value in the table 
materials and energy consumption for simplicity. We found that the costs of producing wood pellets and BIC are 22.8 and $10.9 \mathrm{yen} / \mathrm{kg}$, respectively. Their selling prices are 46 yen $/ \mathrm{kg}$ for pellets and $50 \mathrm{yen} / \mathrm{kg}$ for BIC. From this analysis, we argue that BIC has a higher gross margin than pellets when production is completed.

Overall, producing Bio-coke is less efficient in terms of energy consumption and $\mathrm{CO}_{2}$ emission than producing pellets. Nonetheless, BIC has many benefits such as higher usability and gross margin. Above all BIC can be used in blast furnaces as alternative to coal-coke. If such alternative energy use is established, there is potential for high demand potential in the future.

\section{Effects of $\mathrm{CO}_{2}$ emission reduction using BIC as alternative fuel}

The Bio-coke produced in the plant is used as an alternative to coal-coke at a company in Aichi Prefecture. BIC is a carbon-neutral fuel so its $\mathrm{CO}_{2}$ emissions are not counted at the time of combustion. In other words, use of BIC could avoid $\mathrm{CO}_{2}$ emissions that would otherwise have been created using coal-coke. Indeed, Uchiyama et al. [16] indicates that about 3100 tons of $\mathrm{CO}_{2}$ can be avoided if 1000 tons of coal-coke is replaced by Bio-coke. As indicated in Table 5, 1 ton of BIC can substitute for 0.6 tons of Coal-coke in terms of calorific value and could avoid the emission of $1.86 \mathrm{t} \mathrm{CO}_{2}$. However, these values do not take the $\mathrm{CO}_{2}$ emitted to produce the BIC into account. We thus proceed to clarify the benefits and merits of using BIC by taking into account the $\mathrm{CO}_{2}$ emissions from all the processes involved in BIC production and its use as an alternative to coal cokes.

The $\mathrm{CO}_{2}$ emitted in producing and transporting BIC is $1.01 \mathrm{t} \mathrm{CO}_{2} / \mathrm{t}$, and we assume $0 \mathrm{t} \mathrm{CO} \mathrm{CO}_{2} / \mathrm{t}$ at the time of combustion because BIC is counted as carbon neutral. The $\mathrm{CO}_{2}$ emission factor for coal-coke in this study is $3.17 \mathrm{t}$ $\mathrm{CO}_{2} / \mathrm{t}$ (Table 1). We estimate that one ton of BIC as an alternative to coal-coke can avoid $2.16 \mathrm{t} \mathrm{CO}_{2} /$ t. Calculated in $\mathrm{MJ}, 10.82 \times 10^{-2} \mathrm{~kg} \mathrm{CO} / \mathrm{MJ}$ are produced for coalcoke and $5.44 \times 10^{-2} \mathrm{~kg} \mathrm{CO}_{2} / \mathrm{MJ}$ for BIC. This means that using $1 \mathrm{MJ}$ of $\mathrm{BIC}$ is equivalent to avoiding $5.38 \times 10^{-2} \mathrm{~kg}$ of $\mathrm{CO}_{2}$ emissions.

\section{Conclusion}

In this study, we clarified the $\mathrm{CO}_{2}$ emission as an indicator of environmental impacts and overall benefits of producing and using BIC by looking into the case of a BIC plant in Takatsuki city, Osaka. From the analysis, we conclude the following points:

Most of the $\mathrm{CO}_{2}$ emissions associated with BIC production originates in electricity consumption in the production process. Therefore, achieving reductions in electricity consumption by reviewing the relevant processes will be of vital importance in terms of reducing $\mathrm{CO}_{2}$ emissions. It is important to note that though $\mathrm{CO}_{2}$ emission is assumed during production, as analyzed in the study, alternative use of BIC as fuel can result in a $60 \%$ emission reduction compared to using coal-coke. If cascade recycling of wood becomes a more common source of raw materials, larger $\mathrm{CO}_{2}$ reductions can be expected in the future.

Pellet fuel, produced in the same facility as the BIC, has about the same calorific value as BIC. Pellets have some advantages over BIC in terms of environmental impacts but $\mathrm{BIC}$ has higher gross margin and energy density, which make it ideal for industrial uses like being substituted for coal-coke as described in this study. Pellets might be more suited to use in households and small facilities. Thus, it is essential for these biomass products to be utilized in suitable conditions and purposes, maximizing their merits and usability.

In Japan where forest accounts for $70 \%$ of the country's area, the maintenance of forests has been a very serious problem. Using lumber from forest thinning as a raw material for producing BIC and wood pellets, which could lead to better forest maintenance, has promise in this regard, if their production is promoted. In order to promote forest biomass utilization, considering only environmental aspects is not enough. As mentioned earlier, environmental conservation, economy activity, and area fixity are needed to sustain forestry. BIC, for example, is promising in that if used in industry it can effectively contribute to both environmental conservation and economy activity. In the case of Takatsuki, Osaka, it is important that the OFOA produces $\mathrm{BIC}$ and pellets. Even if production increases rapidly with possible growth of demand, the OFOA will maintain a certain level of environmental concern and area fixity, rather
Table 5 Comparison Bio-coke and coal-coke

\begin{tabular}{llll}
\hline & Bio-coke & Coal-coke & Data source \\
\hline Calorific value $(\mathrm{kcal} / \mathrm{kg})$ & 4438 & 7000 & OFOA interviews \\
Calorific value $(\mathrm{MJ} / \mathrm{t})$ & 18,570 & 29,289 & \\
$\mathrm{CO}_{2}$ emission during production and transport $\left(\mathrm{t} \mathrm{CO}_{2} / \mathrm{t}\right)$ & 1.01 & 3.17 & Bio-coke: this study \\
$\mathrm{CO}_{2}$ emission during combustion $\left(\mathrm{t} \mathrm{CO}_{2} / \mathrm{t}\right)$ & 0 & & Coal-coke: [19] \\
Fuel amounts with equivalent calorific content $(\mathrm{t})$ & 1 & 0.6 & - \\
\hline
\end{tabular}


than giving too much priority to economic considerations (profits). We argue that if forest biomass utilization is vigorously promoted, regional forestry will be revitalized in an effective and sustainable manner, which may positively impact the local area. The promotion of BIC production, then could have positive effects on environmental conservation, economy activity, and area fixity through the use of local resources. It has the potential to contribute not only to resolving global environmental problems, but also to improving Japanese forestry and local sustainability.

Acknowledgments The authors are grateful to the Osaka Prefecture Forest Owners Association, Japan, for providing useful information and data that enabled us to carry out this study.

Open Access This article is distributed under the terms of the Creative Commons Attribution 4.0 International License (http://crea tivecommons.org/licenses/by/4.0/), which permits unrestricted use, distribution, and reproduction in any medium, provided you give appropriate credit to the original author(s) and the source, provide a link to the Creative Commons license, and indicate if changes were made.

\section{References}

1. Berg S, Lindholm EL (2005) Energy use and environmental impacts of forest operations in Sweden. J Clean Prod 13:33-42

2. Carpentieri M, Corti A, Lombardi L (2005) Life cycle assessment (LCA) of an integrated biomass gasification combined cycle (IBGCC) with $\mathrm{CO}_{2}$ removal. Energy Convers Manag 46:17901808

3. Ministry of the Environment of Japan (2003) Kankyo hakusyo for the 2003 (in Japanese). https://www.env.go.jp/policy/hakusyo/ h25/. Accessed 15 Dec 2014

4. Komata H, Orihashi K, Ishikawa Y, Hitoe Y, Hattori N (2010) Life cycle impact assessment of wood pellets made in Hokkaido (in Japanese). Mokuzai Gakkaishi 56:139-148

5. Kinki University, Ida T, Nakanishi A (2006) Solid biomass and method for production thereof. JP patent no. 4089933. 2006-7-27

6. Ida T (2011) The technical production development of advanced alternative coke fuel, bio-coke, by non-carbonized transfer technology. J Jpn Inst Energy 90:2-9

7. Uchiyama T, Okuyama K, Akiyama H (2014) Reduction of coke consumption in high-temperature gasifying and direct melting system. JFE technical report no. 19

8. Honjo T (2008) Biomass solid fuel. J High Temp Soc 34:146-152

9. Mizuno S, Ida T, Fuchihata M (2011) A study of physical properties of high-density solid biomass, bio-coke, with unutilized biomass. J Jpn Soc Exp Mech 11:19-24

10. Goto R, Namba K, Ida T, Mizuno S (2012) Fundamental study on combustibility promotion of Bio-coke. J Smt Process 1:71-78

11. Torii Y, Mizuno S, Nishino K, Ichino Y, Ohmasa M, Sawai T, Ida T, Fuchihata M (2012) Forming characteristics of bio-coke with a mixture of bamboo and carbonized japanese cedar. J Smt Process $1: 63-70$

12. Ida T, Takagi R, Mizuno S, Sanchez E Jr, Namba K (2013) A study on the physical properties as affected by formation conditions of high density bio-solid fuel made from green tea. J Smt Process 2:83-87

13. Kawai Y, Kuwana K, Ida T, Mizuno S, Morita A (2009) The technical development compounded of high density solid fuel under $180^{\circ} \mathrm{C}-20 \mathrm{MPa}$ conditions by a tea scum. J High Temp Soc 35:97-101

14. Ito H, Sakai Y, Ida T, Nakamura Y, Fujita O (2011) Ignition behavior of bio-coke (highly densified biomass fuel) in hightemperature air flows. J Therm Sci Tech Jpn 6:111-122

15. Nakahara T, Yan H, Ito H, Fujita O (2014) Study on one-dimensional steady combustion of highly densified biomass briquette (bio-coke) in air flow. Proc Combust Inst 35:2415-2422

16. Uchiyama T, Okuyama K, Nakayama T, Watanabe J, Akiyama H, Suzuki Y, Oda H, Hoshi Y, Murata H, Tanaka K, Ida T (2012) Decrease in $\mathrm{CO}_{2}$ emission by using bio-coke at high temperature gasifying and direct melting furnace. Trans Jpn Soc Mech Eng 78:1008-1011

17. Ministry of Agriculture, Forestry and Fisheries of Japan (MAFF) (2013) Todouhukenbetsu shinrinritsu zhinkourinritsu (in Japanese). http://www.rinya.maff.go.jp/j/keikaku/genkyou/h24/1. html. Accessed 15 Dec 2014

18. Osaka Prefectural Government (2010) Osaka no shinrin to ringyo (in Japanese). http://www.pref.osaka.lg.jp/attach/217/00021386/ sinrintoringyou2010.pdf. Accessed 15 Dec 2014

19. Ministry of the Environment of Japan (2006) List of calculation methods and discharge coefficients (in Japanese). http://ghg-san teikohyo.env.go.jp/files/calc/itiran.pdf. Accessed 15 Dec 2014

20. Kansai Electric Power Company (KEPCO) (2013) Press release for $\mathrm{CO}_{2}$ emission factors (in Japanese). http://www.kepco.co.jp/ corporate/pr/2013/0729-1j.html. Accessed 15 Dec 2014

21. Hill J, Nelson E, Tilman D, Polasky S, Tiffany D (2006) Environmental, economic, and energetic costs and benefits of biodiesel and ethanol biofuels. PNAS 103:11206-11210

22. Tsuchiya Y, Karasawa K, Satoh T, Tsuji N (2010) Energy consumption in procurement of wood pellets in Japan (in Japanese). Mokuzai Gakkaishi 56:427-436

23. Agency for Natural Resources and Energy (2007) 2005 nendo ikou tekiyousuru hyouzyun hatsuneturyou no kentoukekka to kaiteichi nitsuite (in Japanese). http://www.enecho.meti.go.jp/ statistics/total_energy/pdf/stte_012.pdf. Accessed 15 Dec 2014

24. New Energy and Industrial Technology Development Organization (NEDO) (2013) Result report 2011-2012: research and development on next-generation strategic biomass energy utilization technology (in Japanese). http://www.nedo.go.jp/library/ seika/list_201405/list_201405.html. Accessed 15 Dec 2014

25. Iwaoka $\bar{M}$, Hifumi $\bar{M}$ (2008) The energy consumption and the amount of carbon dioxides emission, in timber production operations (Latter part). J For Mech Soc 655:1-6

26. Hitoe K, Hasegawa T, Hasegawa K, Terazawa K, Yamanaka K, Hattori N (2013) Case study of life cycle assessment of domestic $\operatorname{logs}$ (in Japanese). Mokuzai Gakkaishi 59:269-277

27. Ministry of Agriculture, Forestry and Fisheries of Japan (MAFF) (2012) Final report of utilization possibility for woody waste from earthquake disaster: investigation in Iwate area (2) (in Japanese). http://www.rinya.maff.go.jp/j/riyou/biomass/pdf/bio mass2-4.pdf. Accessed 15 Dec 2014

28. Map Fan Web. http://www.mapfan.com/. Accessed 15 Dec 2014

29. Ministry of Economy, Trade and Industry (METI) (2006) Method of calculation of the energy consumption of transportation of cargo by transport operators (in Japanese). http://www.mlit.go.jp/ common/000168610.pdf. Accessed 15 Dec 014

30. Kansai Electric Power Company (KEPCO) (2014) Karyokuhatsuden ni tsuite (in Japanese). http://www.kepco.co.jp/corporate/ energy/thermal_power/fuel/status.html. Accessed 15 Dec 2014

31. Osaka Pref. Forest Owners Association (2014) Leaflet of shinrin shigen kakou center (in Japanese). http://www.o-forest.org/pdf/ recyclePrice.pdf. Accessed 15 Dec 2014

32. Agency for Natural Resources and Energy (2013) Recent LPG price trends (in Japanese). http://www.japanlpg.or.jp/statistics/ data/20130531.pdf. Accessed 15 Dec 2014 